\title{
STRUČNI ČLANCI
}

\section{KARAKTERISTIKE TRZANJA ELEKTROMAGNETSKOG TOPA}

Ristić B. Zoran,

Ilić S. Slobodan, Kari V. Aleksandar, Vojna Akademija - Katedra vojnih mašinskih sistema, Beograd

UDC: $623.421: 621.318 .3$

\section{Sažetak:}

$U$ radu je razmatrano trzanje elektromagnetskog šinskog topa i upoređeno sa trzanjem konvencionalnog topa sa barutnim punjenjem. Zaključuje se da je kod elektromagnetskog topa trzanje manje nego kod topa sa barutnim punjenjem. Takođe, pokazano je da pri istim uslovima lansiranja upotreba gasne kočnice topa sa barutnim punjenjem može izmeniti karakteristike trzanja i više ih približiti ponašanju elektromagnetskog topa.

Ključne reči: elektromagnetski top, trzanje, top sa barutnim punjenjem, gasna kočnica.

\section{Uvod}

Interesovanje za elektromagnetsko ubrzavanje i lansiranje projekti-

la postoji preko 80 godina. Prvi rezultat praktične vrednosti objavljen je 1970. godine na Nacionalnom univerzitetu Australije. Iz realizovanog prototipa elektromagnetskog topa telo mase $3 \mathrm{~g}$ ispaljeno je brzinom $5900 \mathrm{~m} / \mathrm{s}$. Posle 1980. godine firma Westinghouse realizuje elektromagnetski lanser kojim je projektil mase $317 \mathrm{~g}$ lansiran brzinom $4200 \mathrm{~m} / \mathrm{s}$. Ovaj eksperiment ima veću značajnu praktičnu vrednost, jer masa lansiranog projektila može da se uporedi sa masom potkalibarnog projektila klasičnog topa sa barutnim punjenjem kalibra $35 \mathrm{~mm}$.

$\mathrm{Na}$ programima primene električne energije u elektromagnetskim lanserima koji mogu da realizuju hiperbrzine i hiperenergije lansiranja radi se i u drugim zemljama: Velikoj Britaniji, Nemačkoj, Izraelu, Kanadi, SAD i dr. U poslednjih 10 do 15 godina savremena istraživanja usmerena su na usavršavanje dva moguća rešenja: elektromagnetske topove sa cevnim lanserom i elektromagnetske topove sa šinskim lanserom. 


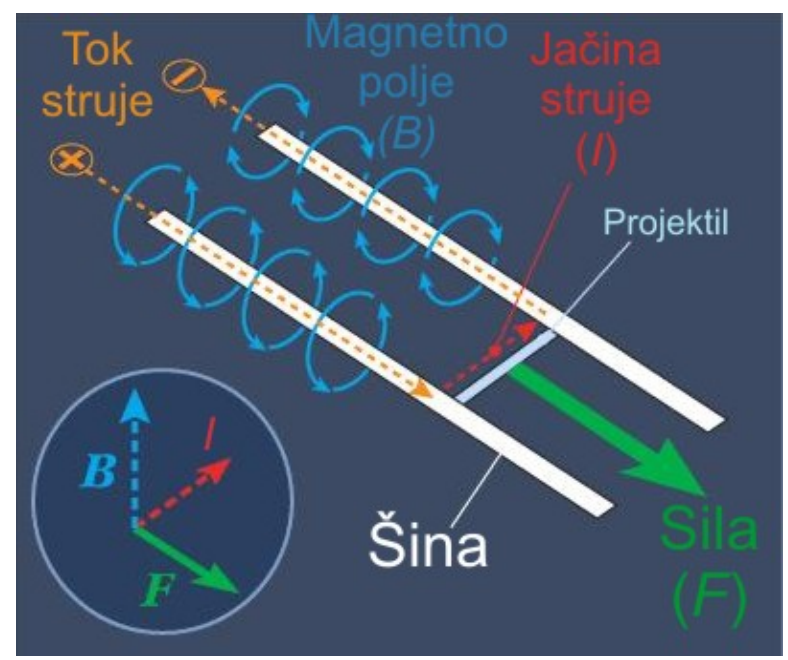

Slika 1 - Šinski elektromagnetski top

$\mathrm{U}$ ovom radu razmatraju se samo jednostavni šinski elektromagnetski topovi čija je principijelna šema prikazana na slici 1 . Oni imaju dve paralelne međusobno izolovane provodničke šine koje se protežu čitavom dužinom lansera. Projektil se ubrzava Lorencovom silom $F_{L}$ koja se razvija iz međusobnog uticaja magnetnog polja formiranog oko šina (zbog strujnog toka kroz jednu i drugu šinu) i struje koja prolazi kroz armaturu.

$U$ šinskom lanseru veličina ove sile definisana je relacijom (1):

$$
F_{L}=\frac{L I^{2}}{2}
$$

gde su:

$L, \frac{\mu H}{m}$ - induktivnost po jedinici dužine šine čije su karakteristične vrednosti $0,35 \div 0,55 \mu H / m$,

$I, A$ - jačina struje.

Lorencova sila $F_{L}$ nije konstantna duž šinske strukture i pojava „skin“ efekta mora se uzeti u obzir. Ako se pretpostavi da je jačina struje konstantna, ubrzanje projektila mase $m_{p}$ je:

$$
a_{p}=\frac{L I^{2}}{2 m_{p}}
$$


Brzina projektila duž elektromagnetskog akceleratora je tada:

$$
v_{p}=\frac{L I^{2}}{2 m_{p}} t
$$

gde je $t$ - vreme kretanja projektila.

Princip funkcionisanja elektromagnetskog šinskog topa je jednostavan [1], ali je u praksi potrebna jednosmerna struja velike jačine (veće od $4 \mathrm{MA}$ ), zbog čega je nužan snažan električni izvor. Tako, na primer, da bi se projektilu mase $1 \mathrm{~kg}$ saopštila kinetička energija od 4,5 MJ, koja je neophodna za dobijanje brzine od $3000 \mathrm{~m} / \mathrm{s}$ (kao što je slučaj sa ispaljivanjem strelastog potkalibarnog projektila $90 \mathrm{~mm}$ iz klasičnog topa) potrebna je snaga od $2 \mathrm{GW}$. To je izuzetno velika snaga za realizaciju borbenog sredstva podobnog za operativnu upotrebu.

Problemi su još izraženiji ako se želi realizacija elektromagnetskog šinskog topa koji bi po performansama odgovarao tenkovskom klasičnom topu $125 \mathrm{~mm}$ čija je masa projektila $8 \mathrm{~kg}$, brzina $2500 \mathrm{~m} / \mathrm{s}$, a dužina cevi $6,25 \mathrm{~m}$. Pod uslovom da je ubrzanje konstantno, a vreme ubrzavanja projektila u cevi $5 \mu$ s potrebna sila za ubrzanje je $4 \mathrm{MN}$. Konverzija mehaničke energije u električnu vrši se pomoću unipolarnih generatora, tj. mašina jednosmerne struje malog napona. Ovi generatori akumuliraju energiju dobijenu od termičkog motora, a kada se priključe proizvode kratke impulse velikog intenziteta koji su neophodni za funkcionisanje elektromagnetskog šinskog akceleratora.

Strujni tok može se obezbediti iz pogodnog pulsirajućeg energetskog sistema i na drugi način (na primer, grupa kondenzatora, akumulatorski redno povezan induktor i sl.). Karakteristika gradijenta induktivnosti je obično $L=$ const, a jačina struje $I$ je vremenski promenljiva veličina, zavisno od karakteristika energetskog sistema koji se koristi. Pošto je strujni tok u šinama u stalnoj interakciji sa magnetnim poljem, razvija se znatna reaktivna (odbojna) sila koju mora da izdrži konstrukcija elektromagnetskog lansera.

Za funkciju elektromagnetskog šinskog topa, pored obezbeđenja vrlo jakih izvora električne snage, bitno je da se, zbog smanjenja velike erozije šina, što više skrati vreme dejstva „plazme“ na šine. Erozija šina je veliki problem šinskih topova, od čijeg uspešnog rešenja zavisi da li će se dobiti borbeni sistem prihvatljivog veka trajanja. Treba ukazati i na teškoće u vezi sa rešenjem komutatora unipolarnog generatora, pa se čine napori da se unipolarni generator zameni monofaznim alternatorom.

Nezavisno od toga kakav će se uređaj ili sistem koristiti za pretvaranje mehaničke energije u električnu, elektromagnetski šinski topovi imaju značajne prednosti u odnosu na klasične koncepcije topova. Ove prednosti ogledaju se u sledećem:

- projektili elektromagnetskih šinskih topova su manjih dimenzija i mase u odnosu na klasične projektile sa čaurom, 
- udarna energija projektila elektromagnetskih šinskih topova na jedinici površine cilja je veća, pa su sredstva efikasnija u protivoklopnoj borbi,

- zbog izmenjene koncepcije projektila, konstrukcija zadnjaka, zatvarača sa izbacačem čaura, kao i automatskog punjača znatno se pojednostavljuje,

- pošto nema dejstva ističućih barutnih gasova (reaktivna sila pritiska na dno cevi) trzanje je veoma malo, pa nema ni potrebe za ugradnjom protivtrzajućeg uređaja,

- nema štetnog dejstva udarnog talasa, bleska i dima koji obično prate ispaljivanje klasičnih projektila.

lako je još rano da se govori o svim prednostima i nedostacima elektromagnetskih topova, do sada su uočeni sledeći nedostaci:

- intenzivno elektromagnetsko zračenje, koje protivnik može lako da otkrije, javlja se čak i pre lansiranja prvog projektila,

- do termičkog zračenja elektromagnetskih šinskih topova može doći i pre lansiranja prvog projektila,

- potrebna je dodatna zaštita posade - posluge od navedenih štetnih zračenja.

U dostupnoj literaturi postoji relativno mali broj stručnih radova o elektromagnetskim topovima, pa je svako novo saznanje i objavljeni materijal o ovom problemu interesantan i dragocen.

\section{Trzanje topa}

Kod topova sa barutnim punjenjem sila ubrzanja projektila obezbeđuje se visokim pritiskom barutnih gasova koji nastaju sagorevanjem barutnog punjenja za vreme opaljenja. Reaktivno dejstvo pritiska barutnih gasova ne prenosi se na zadnjak sa zatvaračem stvarajući silu trzanja $P_{k n}$. Integral po vremenu ove sile je impuls trzanja $I_{t}$ i za top sa barutnim punjenjem jednak je količini kretanja projektila i barutnih gasova na ustima cevi. Prema tome, može se napisati relacija:

$$
I_{t}=\int_{0}^{t_{k}} P_{k n} d t=\left(m_{p}+\beta m_{b}\right) v_{0}
$$

gde su:

$P_{k n} \quad$ - sila trzanja (rezultujuća sila na dno kanala cevi),

$m_{p}, m_{b}$ - masa projektila i barutnog punjenja,

$t_{k} \quad-$ vreme ukupnog dejstva sile trzanja na cev,

$\beta \quad-$ koeficijent naknadnog dejstva barutnih gasova. 
Relacija (4) važi za tzv. slobodno trzanje cevi, tj. kretanje cevi unazad za vreme opaljenja usled reaktivne sile pritiska barutnih gasova bez sila otpora kretanju ili kočenja kretanja usled dejstva protivtrzajućeg uređaja.

U slučaju elektromagnetskog topa nema ni zadnjaka sa zatvaračem ni barutnih gasova, pa je impuls trzanja jednostavno jednak količini kretanja projektila na ustima cevi $I_{t}=m_{p} v_{0}$. U vezi s tim nameće se pitanje kako je primenjena i gde postoji sila trzanja?

Ćinjenica da na osnovu prvog principa mehanike elektromagnetski topovi trzaju dokazana je merenjem utvrđenog elektromagnetskog topa $u$ balističko klatno [2]. Prema mišljenju Vitalisa (Witalis) [2] sila trzanja prenosi se u samim delovima šina i malog je intenziteta. Maršal (Marshall) i Vud (Wood) [3] osporavaju njegove tvrdnje da se sila trzanja kod elektromagnetskih topova može zanemariti i uzimaju da ona postoji i održava se u provodničkim šinama čitavom dužinom lansera. Jasno je da provodničke (radne) šine koje povezuju strujno kolo i top unose znatno opterećenje u sistem, pa je neophodno da se eksperimentalna merenja izvrše vrlo pažljivo i pouzdanije definiše mesto dejstva sile trzanja. $U$ tom smislu njihovo gledište je korektnije i za dalje analize prihvatljivije.

Radi uporedne analize sa topom klasične konstrukcije sa barutnim punjenjem impuls trzanja je određen kao suma količine kretanja projektila $i$ isticanja barutnih gasova na ustima cevi [3]:

$$
\begin{aligned}
& I_{t}=m_{p} v_{0}+m_{b} \sqrt{R T_{0}} \cdot\left(\frac{2}{\kappa+1}\right)^{\frac{3}{2}}\left[1+(\kappa+1) \frac{m_{b}}{12 \kappa m_{p}}\right] \\
& R T_{0}=R T_{a}-0,26\left(\frac{1}{6}+\frac{4 m_{p}}{7 m_{b}}\right) v_{0}^{2}
\end{aligned}
$$

gde su:

$R \quad$ - gasna konstanta,

$\kappa \quad$ - odnos specifičnih toplota i

$T_{a}, T_{0}$ - adijabatska temperatura i srednja temperatura gasa na izlazu iz cevi.

S obzirom na relaciju (4) trend rasta impulsa trzanja sa brzinom na jednostavan način može se utvrditi preko zavisnosti brzine na ustima cevi i relativnog odnosa mase punjenja i projektila, čiji je oblik [3]:

$$
v_{0}=3050 \sqrt{\frac{\mu}{\mu+3}}
$$

gde je $\mu=\frac{m_{b}}{m_{p}}-$ odnos mase barutnog punjenja i projektila. 
Grafički prikaz uzajamnih odnosa prema (7) dat je na slici 2.

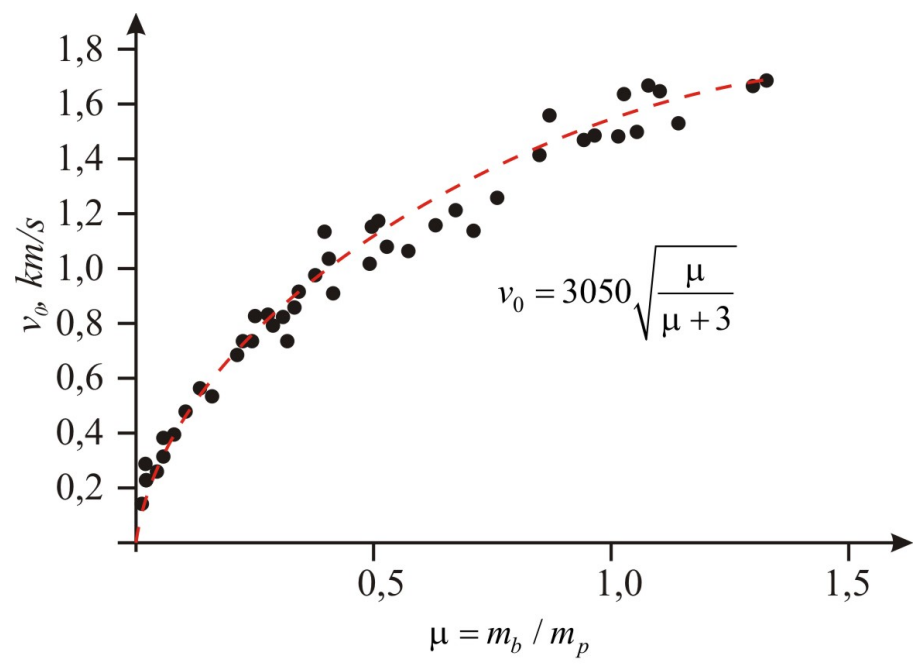

Slika 2 - Brzina u funkciji odnosa masa

Koristeći relaciju (7) posle sređivanja članova jednačine (5) i (6) mogu se sada napisati u pogodnijem obliku radi proračuna i poređenja sa impulsom trzanja za elektromagnetski top.

$$
\begin{aligned}
& \frac{I_{t}}{m_{p}}=3050 \sqrt{\frac{\mu}{\mu+3}}+\mu \sqrt{R T_{0}} \cdot\left(\frac{2}{\kappa+1}\right)^{\frac{3}{2}} \cdot\left[1+(\kappa+1) \frac{m_{b}}{12 \kappa m_{p}}\right] \\
& R T_{0}=R T_{a}-2,4\left(\frac{1}{6}+\frac{4}{7 \mu}\right) \frac{\mu}{\mu+3}
\end{aligned}
$$

Kao primer proračuna odgovarajućih veličina i impulsa trzanja uzet je top kalibra $20 \mathrm{~mm}$, čiji projektil koristi barut oznake WC870. Za ovaj slučaj usvojene vrednosti ostalih veličina su: $R=365,5 \mathrm{~m}^{2} / \mathrm{Ks}^{2}, T_{a}=2577 \mathrm{~K}$ i $\mathrm{k}=1,25$.

Promena odnosa impulsa za top $20 \mathrm{~mm}$ sa barutnim punjenjem je numerički određena i prikazana na slici 3, a zatim upoređena sa promenom odnosa impulsa za elektromagnetski top prema:

$$
\frac{I_{t}}{m_{p}}=v_{0}
$$




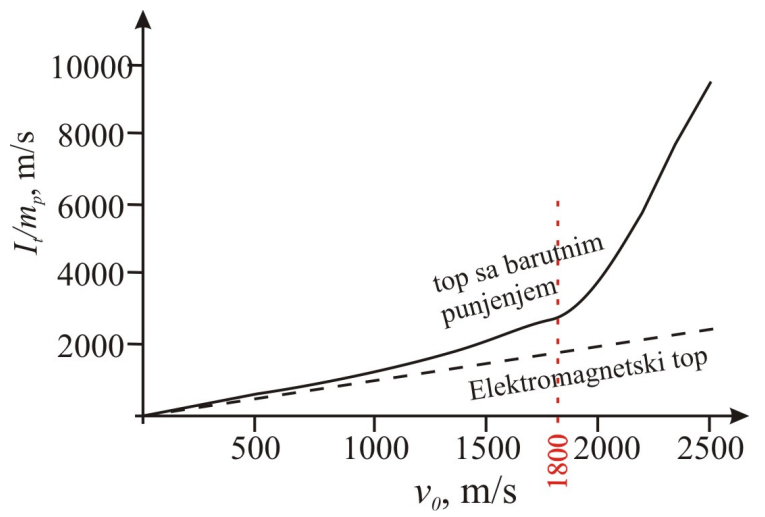

Odnos prema relaciji (10) u stvari predstavlja impuls trzanja koji se saopštava elektromagnetskom topu pri opaljenju sa konstantnom lansiranom masom. Može se videti, prema slici 3, da su impulsi trzanja topa sa barutnim punjenjem i elektromagnetskog topa vrlo slični pri manjim brzinama, a da preko $v_{0}=1800 \mathrm{~m} / \mathrm{s}$ impuls trzanja klasičnog topa naglo raste sa porastom mase barutnog punjenja.

Često se procena impulsa trzanja simulira preko više brzina lansiranja projektila koje treba da obezbede konstantnu energiju $E_{u}$ na ustima cevi.

Ponašanje elektromagnetskog topa ukazuje na činjenicu da je impuls trzanja promenljiv kao energija podeljena sa brzinom. Ranije je utvrđeno da je impuls sile trzanja topa sa barutnim punjenjem sličan kao impuls sile trzanja kod elektromagnetskog topa (do brzine od $v_{0}=1800 \mathrm{~m} / \mathrm{s}$ počinje brzo da raste). Međutim, u slučaju konstantne energije ovaj porast impulsa je blaži usled smanjenja lansirane mase i mase punjenja kada brzina raste (slika 4).

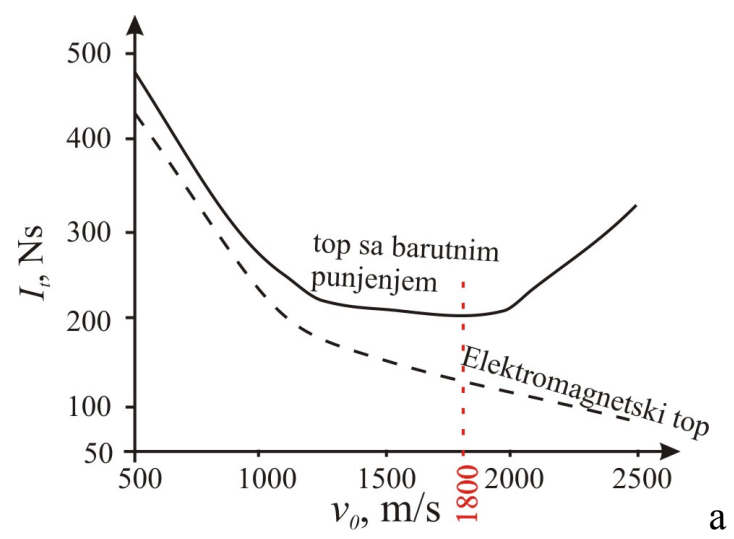

Slika 4 - Odnos impulsa u slučaju $E_{u}=$ const 
Pošto su topovi sa barutnim punjenjem klasične koncepcije obično snabdeveni gasnom kočnicom, to za razliku od elektromagnetskih topova postoji mogućnost smanjenja impulsa trzanja usled dejstva gasne kočnice.

\section{Uticaj gasne kočnice}

Gasna kočnica, kao gasni uređaj na ustima cevi, odbija izlazne barutne gasove kroz odgovarajuće površine bočnih otvora, stvarajući silu kočenja u aksijalnom smeru. Postoji više vrsta i tipova gasnih kočnica sa različitim stepenom iskorišćenja energije izlazne struje barutnih gasova, odnosno koeficijenta korisnog dejstva.

Na slici 5 prikazana je gasna kočnica M109 velike efikasnosti koja je primenjena na samohodnoj haubici $155 \mathrm{~mm}$.

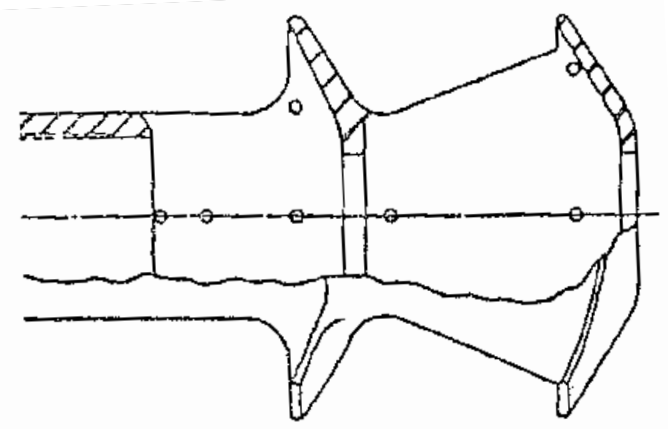

Slika 5 - Izgled gasne kočnice M109

Ova gasna kočnica je interesantna, jer su Baur (Baur) i Šmit (Schmidt) [4] sa njom, kao i sa gasnom kočnicom M198, merili kočenje trzanja, odnosno njegovo smanjenje na modelu topa $20 \mathrm{~mm}$. Dobijeni rezultati promene efikasnosti za obe gasne kočnice dati su grafičkim prikazom na slici 6.

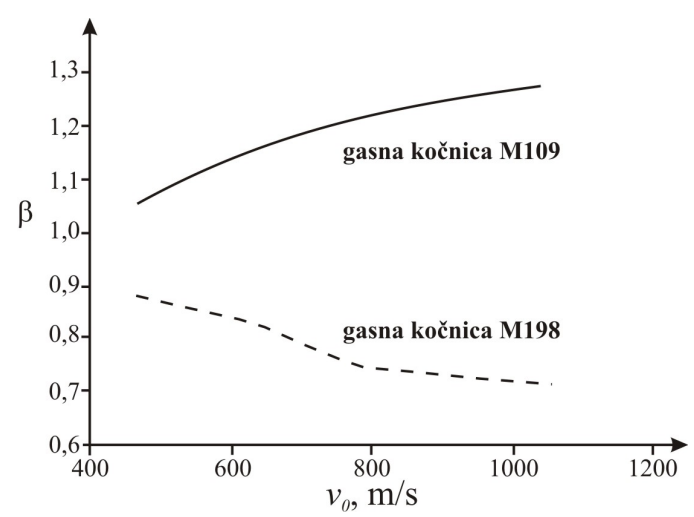

Slika 6 - Efikasnost gasne kočnice 
Koeficijent efikasnosti gasne kočnice $\beta$ definiše se kao odnos relativne promene momenta trzanja sa gasnom kočnicom i bez nje masenog sistema koji čine cev, projektil i barutni gasovi (punjenje).

Relacija za koeficijent efikasnosti $\beta$ data je u obliku [4]:

$$
\beta=\frac{I_{0}-I_{g}}{I_{0}-m_{p} v_{0}}
$$

gde su:

$I_{0}-I_{g}$ - razlika ukupnog impulsa trzanja sa gasnom kočnicom i bez nje $\mathrm{i}$

$I_{0}-m_{p} v_{0}$ - razlika ukupno raspoloživog impulsa trzanja u barutnim gasovima.

Veličina koeficijenta efikasnosti $\beta$ može biti veća od 1 (efikasnost preko $100 \%$ ) ako barutni gasovi u gasnoj kočnici mogu da se šire i napred i nazad, kao u slučaju gasne kočnice M109 reaktivnog tipa i prečnika dva kalibra, prema slici 6 .

Za top $20 \mathrm{~mm}$ sa porastom početne brzine raste i pritisak na ustima cevi. Gasna kočnica M198 je prečnika 1,6 kalibara i aktivnog je tipa, pri čemu spoljne pregrade omogućavaju gasovima da napuste cev sa porastom produkata sagorevanja. Pregrade apsorbuju više produkata sagorevanja ako pritisak barutnih gasova i efikasnost gasne kočnice rastu. Supersonično jezgro produkata sagorevanja pri tome može potpuno da obuhvati obe površine gasne kočnice i promene brzine (pritiska) na izlaznom preseku kočnice. Ovaj podatak prema [3] mogao bi da se iskoristi za proračun dozvoljenog impulsa topa kada su brzine povećane i izuzetno velike.

Na osnovu podataka za gasnu kočnicu M109, prema slici 6, ekstrapolacijom brzina do $2500 \mathrm{~m} / \mathrm{s}$, impuls trzanja topa sa barutnim punjenjem sa visokoefikasnom gasnom kočnicom može se uporediti sa impulsom trzanja elektromagnetskog topa na sličan način, prema slici 7.

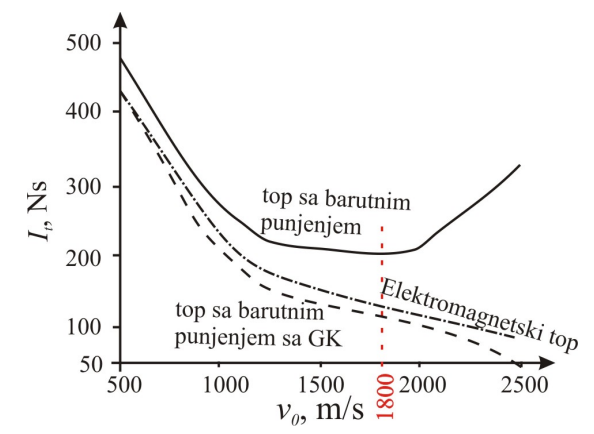

Slika 7 - Promena impulsa trzanja sa gasnom kočnicom pri $E_{u}=$ const

Kako je efikasnost gasne kočnice M109 veća od 1, ukupni impuls saopšten topu sa barutnim punjenjem sa ugrađenom kočnicom je manji nego impuls trzanja elektromagnetskog topa, tj. moment količine kretanja sa- 
opšten projektilu. lako gasna kočnica topa sa barutnim punjenjem znatno smanjuje razliku u impulsima trzanja između klasične koncepcije topa i elektromagnetskog topa, postoje neki nedostaci u pogledu primene gasnih kočnica o kojima treba da se vodi računa. Naime, gasna kočnica M109 je vrlo masivna i utiče na funkcionalnost topa i projektovanje mehanizma za usmeravanje cevi po pravcu i elevaciji. Upotreba ovakve visokoenergetske gasne kočnice, takođe, znatno povećava efekte na ustima cevi (pucanj, blesak i sl.) i natpritisak iza oruđa. Međutim, u slučaju ugradnje topa na borbena vozila sa zatvorenom kupolom to ne mora da bude veći problem.

\section{Zaključak}

Na osnovu izvršene analize impulsa trzanja i karakterističnih veličina koje utiču na veličinu ovog impulsa utvrđeno je da elektromagnetski top ima manji impuls trzanja nego top klasične koncepcije sa barutnim punjenjem. To se i moglo očekivati, s obzirom na specifičnosti konstruktivnog rešenja navedenih sredstava. Izrazite razlike u impulsima trzanja nastaju naročito pri velikim početnim brzinama $v_{0} \geq 1800 \mathrm{~m} / \mathrm{s}$ u slučaju topa kalibra $20 \mathrm{~mm}$. Poređenjem ostvarenih impulsa trzanja elektromagnetskog topa i topa klasične konstrukcije sa izuzetno efikasnom gasnom kočnicom vidi se da se može ostvariti znatno smanjenje impulsa trzanja topa sa barutnim punjenjem i značajno približenje impulsima trzanja koje ostvaruje elektromagnetski top. Pri velikim početnim brzinama projektila $v_{0} \geq 2000 \mathrm{~m} / \mathrm{s}$ (slika 7), kod topova sa barutnim punjenjem može se ostvariti i znatno smanjenje impulsa trzanja koji može biti i znatno manji od impulsa trzanja elektromagnetskog topa.

Pitanje impulsa trzanja elektromagnetskih topova značajno je sa više aspekata, kao što su: stabilnost sistema pri lansiranju projektila, potreba ugradnje protivtrzajućeg uređaja, koncepcija protivtrzajućeg uređaja, korišćenje energije trzanja za rad mehanizama oruđa i dr. Zbog toga, ali i drugih istaknutih problema koji prate ostvarenje elektromagnetskih topova (snažni izvori električne struje, hlađenje izvora energije i samog oruđa, dimenzije elektromagnetskih topova), pitanje razvoja elektromagnetskih topova i dalje zahteva vrlo opsežna i zahtevna istraživanja i posebnu pažnju.

\section{Literatura}

[1] Ristić, Z., Jakovljević M., Osnovi naoružanja, VA Beograd, 2003.

[2] Witalis, E., Origin, Location, Magnitude and Consequences of Recoil in Plasma Armature Railgun, IEEE, Vol 142, No 3, 1995.

[3] Schmidt, E., Recoil Characteristics of Electromagnetic Cannon, Army Research Laboratory, Aberdeen Proving Ground, MD 21005-5066, 1998.

[4] Baur, E., Schmidt, E., Relationship between Efficiency and Blast from Gas Dynamic Recoil Brakes, AIAA Paper 85-1718, 1985. 
RECOIL CHARACTERISTICS OF AN ELECTROMAGNETIC RAIL GUN

Summary:

In this paper the electromagnetic rail gun recoil is discussed and compared with the recoil of a conventional, propellant gas driven gun. It is shown that, under similar launch conditions, the recoil of an electromagnetic gun is weaker than that of the powder-driven gun. The use of a muzzle brake on a powder-driven gun can alter its recoil characteristics and make its behavior closer to that of the electromagnetic rail gun.

Key words: electromagnetic rail gun, recoil, propellant gas driven gun, muzzle brake.

Datum prijema članka: 15. 07. 2008.

Datum dostavljanja ispravki rukopisa: 26. 01. 2009.

Datum konačnog prihvatanja članka za objavljivanje: 09. 02. 2009. 